\title{
High Dickkopf-1 expression is associated with poor prognosis in patients with advanced urothelial carcinoma
}

\author{
CHENG-HUANG SHEN ${ }^{1,2,4}$, HSIAO-YEN HSIEH ${ }^{1}$, YUAN-HUNG WANG ${ }^{5,6}$, SYUE-YI CHEN ${ }^{1}$, \\ CHUN-LIANG TUNG ${ }^{3}$, JIANN-DER WU ${ }^{3}$, CHANG-TE LIN ${ }^{2}$, MICHAEL W.-Y. CHAN ${ }^{4}$, \\ CHENG-DA HSU ${ }^{1,4}$ and DECHING CHANG ${ }^{4}$
}

\begin{abstract}
Departments of ${ }^{1}$ Medical Research, ${ }^{2}$ Urology, and ${ }^{3}$ Pathology, Chiayi Christian Hospital; ${ }^{4}$ Institute of Molecular Biology, National Chung Cheng University, Chiayi; ${ }^{5}$ School of Public Health, and ${ }^{6}$ Center of Excellence

for Cancer Research, Taipei Medical University, Taipei, Taiwan, R.O.C.
\end{abstract}

Received June 4, 2010; Accepted July 20, 2010

DOI: $10.3892 / \mathrm{etm} .2010 .134$

\begin{abstract}
Although Dickkopf-1 (DKK1) has been demonstrated to be associated with tumorigenesis in various types of human tumors, a correlation between DKK1 and urothelial carcinoma (UC) has not been reported. In the present study, the correlation between DKK1 expression and UC progression was investigated. Seventy-five UC patients were enrolled. The expression of DKK1 in serum and UC tissue was detected by ELISA, real-time PCR and Western blotting. Prognostic significance was assessed by using Kaplan-Meier survival estimates and log-rank tests. The results showed that serum levels of DKK1 were significantly higher in the UC patients with muscle-invasive $(\mathrm{p}=0.0001)$ and high-grade tumors $(\mathrm{p}=0.00001)$ as compared to the controls. A high-serum DKK1 was also associated with poor disease-free survival in the UC patients (hazard ratio $=2.44 ; 95 \%$ CI 1.10-5.40; $\mathrm{p}=0.028$ ). Furthermore, DKK1 was also overexpressed in $93 \%$ (41/44) of the UC tissues. Therefore, the findings indicate that the expression of DKK1 is associated with UC progression.
\end{abstract}

\section{Introduction}

Urothelial carcinoma (UC), also known as transitional cell carcinoma, is a malignant tumor arising from a transitional type of stratified epithelium, the urothelium, and affects the renal collecting system (1). It is the most common cancer of the urinary bladder and ureter (1) and the second leading

Correspondence to: Dr Cheng-Da Hsu, Department of Medical Research, Chiayi Christian Hospital, 539 Chung Hsiao Road, Chiayi 600, Taiwan, R.O.C.

E-mail: 06390@cych.org.tw

Dr Deching Chang, Institute of Molecular Biology, National Chung Cheng University, 168 University Road, Min-Hsiung, Chiayi 621, Taiwan, R.O.C.

E-mail:biodcc@ccu.edu.tw

Key words: urothelial carcinoma, Dickkopf-1, disease-free survival cause of death among malignancies of the genitourinary tract system (2). In the case of bladder cancer, most diagnosed patients have non-muscle invasive disease with a high risk of recurrence (3). Therefore, approaches for the determination of bladder cancer recurrence are important in medical care (4). At present, cystoscopic examination is recommended every 3-6 months for 3 years after surgical treatment (5). Cystoscopy in combination with urinary cytology is the standard protocol for the detection and surveillance of bladder cancer.

Recently, Dickkopf-1 (DKK1) was found to be associated with the development of several types of cancer, including Wilm's tumor, hepatoblastoma, hepatocellular carcinoma, colorectal cancer, lung and esophageal carcinomas, breast, cervical, endometrial and kidney cancers (6-10). DKK1 is a secreted protein that plays a crucial role in head formation during vertebrate development and specifically inhibits Wnt/ $\beta$-catenin signaling (11). DKK1 binds to the LRP5/6 and Kremen proteins leading to LRP endocytosis, which prevents the formation of the Wnt-Frizzled-LRP5/6 receptor complex (12). Furthermore, the Wnt signaling pathway was found to be involved in the pathogenesis of UC (13-19). Therefore, an association of DKK1 expression with UC is a reasonable speculation. To date, the significance of DKK1 activation in human $\mathrm{UC}$ is still not clear. In this study, the correlation between DKK1 expression and UC progression was investigated.

\section{Materials and methods}

Subjects. Seventy-five UC patients who underwent surgery at the Department of Urology, Chiayi Christian Hospital, were enrolled in the study. Seventy-five age-matched cancer-free volunteers were recruited as control individuals. Tumor specimens, blood samples and demographic information (including age, gender and smoking status) were collected at the time of enrollment. Informed consent was obtained prior to the collection of specimens and demographic information. The specimens were collected and stored according to the protocols approved by the Institutional Review Board of the Chiayi Christian Hospital. The clinical features of the UC patients are listed in Table I. 
Table I. Characteristics of the 75 patients with urothelial carcinoma.

\begin{tabular}{|c|c|}
\hline Characteristic & No. of patients $(\%)$ \\
\hline \multicolumn{2}{|l|}{ Age, years } \\
\hline Median & \\
\hline Range & \\
\hline \multicolumn{2}{|l|}{ Gender } \\
\hline Male & $59(78.7)$ \\
\hline Female & $16(21.3)$ \\
\hline \multicolumn{2}{|l|}{ Surgery } \\
\hline \multicolumn{2}{|l|}{ Cigarette smoking } \\
\hline Never & $59(78.7)$ \\
\hline Ever & $16(21.3)$ \\
\hline \multicolumn{2}{|l|}{ Clinical stage } \\
\hline $\mathrm{Ta} / \mathrm{T} 1$ & $35(46.7)$ \\
\hline $\mathrm{T} 2$ & $19(25.3)$ \\
\hline $\mathrm{T} 3$ & $16(21.3)$ \\
\hline $\mathrm{T} 4$ & $5(6.7)$ \\
\hline \multicolumn{2}{|l|}{ Histological grade } \\
\hline Low (G1 or $\mathrm{G} 2$ low) & $16(21.3)$ \\
\hline High (G2 high and above) & $59(78.7)$ \\
\hline \multicolumn{2}{|l|}{ Serum DKK1 (pg/ml) } \\
\hline Median & \\
\hline Range & \\
\hline
\end{tabular}

TURBT, transurethral resection for bladder tumor.

Detection of serum DKK1 by ELISA. Serum DKK1 was detected using the DuoSet ELISA Development System (R\&D System, Minneapolis, MN, USA) according to the manufacturer's instructions. Briefly, a rabbit polyclonal antibody against DKK1 was coated onto a 96-well microplate and incubated overnight at room temperature. After washing, $300 \mu \mathrm{l}$ of Reagent Diluent was added to each well and incubated at room temperature for $1 \mathrm{~h}$. After further washing, $100 \mu \mathrm{l}$ of serum or standard in the Reagent Diluent was added to each well and incubated for $2 \mathrm{~h}$ at room temperature. After further washing, $100 \mu \mathrm{l}$ of a biotinylated goat anti-human DKK1 antibody diluted in Reagent Diluent (50 ng/ml) was added to each well and incubated for $2 \mathrm{~h}$. After subsequent washing, $100 \mu \mathrm{l}$ of the working solution (1:200) containing horseradish peroxidase (HRP)-streptavidin was added to each well and incubated for $20 \mathrm{~min}$. After subsequent washing, $100 \mu \mathrm{l}$ of substrate solution was added to each well for $20 \mathrm{~min}$. The reaction was terminated by adding $50 \mu \mathrm{l}$ of Stop Solution. Each well was assayed using a microplate reader at a $450-\mathrm{nm}$ wavelength.

Statistical analysis. Statistical analysis was performed using the SPSS software version 11 for Windows (SPSS Inc., Chicago, IL, USA). In the statistical analysis, clinical disease stage and tumor grade were stratified as a binary variable, with non-muscle invasive disease (pT1 or pTa) compared to muscle-invasive disease (pT2, pT3 or pT4), and with low grade (G1 or G2 low) compared to high grade (G2 high or above) tumors. The serum DKK1 level was defined as a binary variable, with a serum DKK1 cut-off level of $<1,049 \mathrm{pg} / \mathrm{ml}$ being compared to a serum DKK1 $\geq 1,049 \mathrm{pg} / \mathrm{ml}$. Demographic and clinical information was compared across serum DKK1 levels using the Pearson test. The difference in the levels of DKK1 between the tumor and control groups was analyzed by the Mann-Whitney U test. Disease-free survival (DFS) was calculated from the date of surgery to the date of recurrence or last known date without recurrence. Overall survival (OS) was calculated from the date of surgery to the date of death or last known date that the patient was alive. DFS and OS were calculated by the Kaplan-Meier method. The Cox proportional hazards model was used to evaluate the effect of serum DKK1 level on DFS and OS. Two-sided p-values of $<0.05$ were considered significant.

Detection of DKK1 expression in UC tissues by RT-PCR. The DKK1 gene product was detected by semi-quantitative reverse transcription-PCR (RT-PCR). Total RNA was extracted from tumor tissues with TRIzol (Invitrogen, Carlsbad, CA, USA) following the manufacturer's instructions. Reverse transcription of mRNA to cDNA was performed using random hexamers as reaction primers (Roche Diagnostics, Indianapolis, IN, USA) and SuperScript II (Invitrogen). Semiquantitative RT-PCR was carried out with two sets of primers, 5'-TAGAGTCTAGAACGCAAGGATCTC-3' and 5'-CAA AAACTATCACAGCCTAAAGGG-3', specific to $D K K 1$; and a set of primers, 5'-GAGGTGATAGCATTGCTTTCG-3' and 5 '-CAAGTCAGTGTACAGGTAAGC-3', specific to $\beta$-actin as an internal control.

Detection of DKK1 protein in UC tissues by Western blotting. Expression of DKK1 protein in UC tissues was detected by Western blotting. Total protein of the tissues was extracted and determined usingthea Bio-Rad protein assay (Bio-Rad, Hercules, CA, USA). The tissue extracts were resolved on denaturing polyacrylamide gels and then transferred to a PVDF membrane. After blocking with 3\% blocker (Bio-Rad) in TBS Tween-20 (TBST), the membrane was incubated with a rabbit polyclonal antibody against human DKK1 (hDKK1; Santa Cruz Biotechnology, Santa Cruz, CA, USA) for $2 \mathrm{~h}$ at room temperature. After washing, the membrane was incubated with an HRP-conjugated secondary antibody (Santa Cruz Biotechnology) for $1 \mathrm{~h}$ at room temperature. The membrane was washed with TBST and developed using the enhanced OPTI-4CN Colorimetric Detection kit (Bio-Rad).

\section{Results}

Serum DKK1 levels in UC patients. The DKK1 levels from the sera of 75 UC patients and 75 cancer-free control individuals were examined by ELISA. Serum DKK1 levels in the UC patients were significantly higher than those in the control individuals $(\mathrm{p}=0.00001)$ (Fig. 1A). The Spearman correlation study revealed that none of the prognostic parameters correlated with the serum DKK1 levels, except that both clinical stage and histological grade showed mild correlations with serum DKK1 levels ( $\mathrm{r}=0.357$ and 0.392 , respectively) (Table II). Furthermore, in the subgroup analyses the serum DKK1 levels in the non-muscle invasive and muscle-invasive 

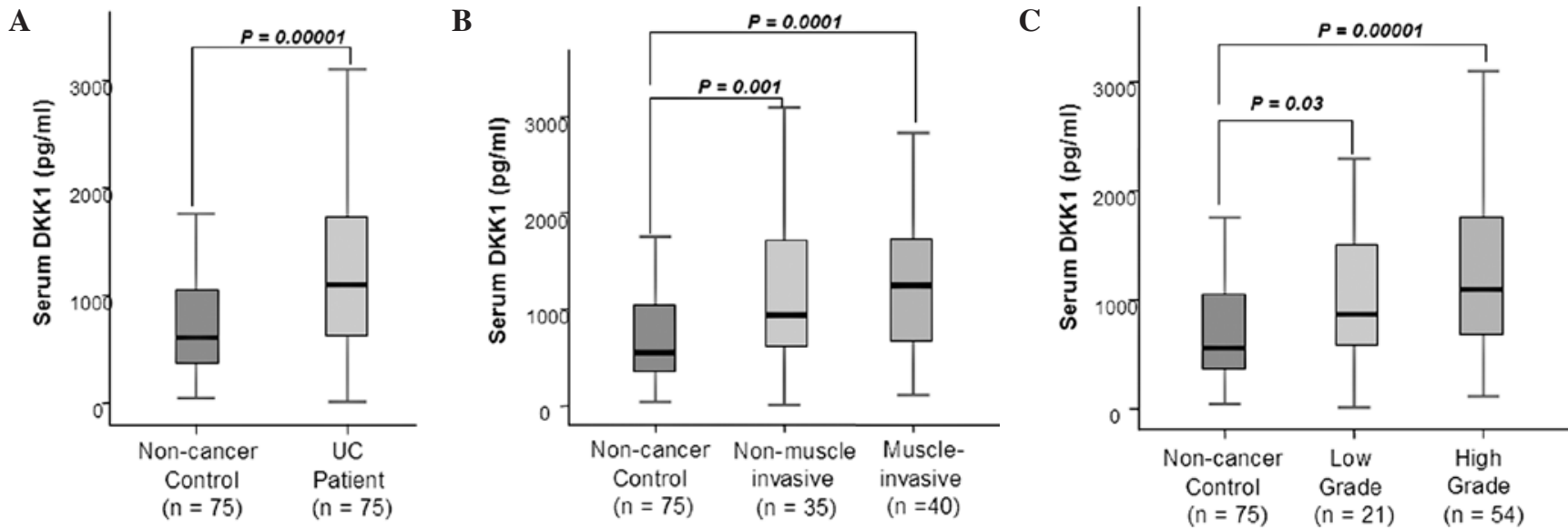

Figure 1. Comparison of serum DKK1 levels in UC patients and non-cancer control individuals. (A) Serum DKK1 levels in UC patients and non-cancer controls was compared. (B) Serum DKK1 levels in the non-muscle invasive and muscle-invasive UC patient subgroups was compared to the non-cancer controls. (C) Serum DKK1 levels in the low-grade and high-grade UC patient subgroups was compared to the non-cancer controls. The whiskers correspond to the largest and smallest non-outlier values from each dataset.

Table II. Spearman correlation coefficients $\left(\mathrm{r}_{\mathrm{s}}\right)$ for the relationships between serum DKK1 and different variables in patients with urothelial carcinoma.

\begin{tabular}{lrr}
\hline Variable & $\mathrm{r}_{\mathrm{s}}$ & $\mathrm{p}$-value \\
\hline Age $(1$ year) & 0.104 & 0.206000 \\
Gender (male $\rightarrow 0$, female $\rightarrow 1$ ) & -0.027 & 0.738000 \\
Cigarette smoking $($ never smoker $\rightarrow 0$, smoker $\rightarrow 1$ ) & -0.040 & 0.626000 \\
Clinical stage (control $\rightarrow 0$, non-muscle invasive $\rightarrow$, muscle invasive $\rightarrow 2)$ & 0.357 & 0.000010 \\
Histological grade $($ control $\rightarrow 0$, low $\rightarrow 1$, high $\rightarrow 2)$ & 0.392 & 0.000001
\end{tabular}

groups of UC patients were significantly higher than the levels in the cancer-free control group $(\mathrm{p}=0.01$ and 0.001 , respectively) (Fig. 1B). In addition, when the histological grades of the UC tumors were considered, the serum DKK1 levels in patients with low-grade and high-grade tumors were higher than those in the non-cancer control individuals ( $\mathrm{p}=0.03$ and 0.0001, respectively) (Fig. 1C).

Correlation of serum DKK1 levels with overall survival of UC patients. To define high DKK1 expression, the cut-off value for a high expression level was determined from the dataset covering the 75 UC patients and 75 control individuals using ROC curve analysis. The optimum cut-off value in this study was determined to be $1,049 \mathrm{pg} / \mathrm{ml}$, which gave a sensitivity of $52 \%$ and a specificity of $80 \%$. Based on this definition, a serum DKK1 level $\geq 1,049 \mathrm{pg} / \mathrm{ml}$ was considered high expression. Analyses of the influence of serum DKK1 on OS showed that the survival time of UC patients with high-serum DKK1 expression was shorter than that of patients with low-serum DKK1 expression. However, this difference showed only a marginal significance $(\mathrm{p}=0.063)$ (Fig. 2A). Univariate and multivariate analyses showed that age, gender, cigarette smoking status, clinical stage and histological grade were not significantly associated with OS (Table III).

Correlation of serum DKK1 levels with disease-free survival of UC patients. Univariate analyses was used to assess the influence of serum DKK1 levels on DFS among the UC patients. The median DFS was found to be 11 months [95\% confidence interval (CI) 5-17] for patients with high expression of serum DKK1 vs. 33 months (95\% CI 0-90) for those with low expression of serum DKK1 (Fig. 2B). The difference in DFS was statistically significant $(\mathrm{p}=0.028)$ (Table III). When serum DKK1 was defined as a continuous variable, the risk of recurrence was found to increase as the level of serum DKK1 increased ( $\mathrm{p}=0.007$; Table III). Univariate and multivariate analyses showed that age, gender, cigarette smoking status, clinical stage and histological grade were not associated with DFS (Table III).

Expression of DKK1 in UC tissues. The results described above demonstrated that serum DKK1 levels in UC patients were higher than those in the control individuals. Yet, whether the expression of DKK1 was also higher in UC tissues compared with normal tissues was still undetermined. Since previous studies revealed that the expression of DKK1 was elevated in lung and esophageal cancer tissues (20-25), the expression of DKK1 in UC tissues was examined. Forty-four UC tissue samples from the $75 \mathrm{UC}$ patients were available for examination. Results of the RT-PCR analysis showed that high expression of DKK1 was found in 93\% (41/44) of the examined UC tissues (Fig. 3A). Furthermore, 10 UC tissues with adjacent normal tissues were examined for DKK1 protein expression by Western blotting. The results showed that the expression 
A

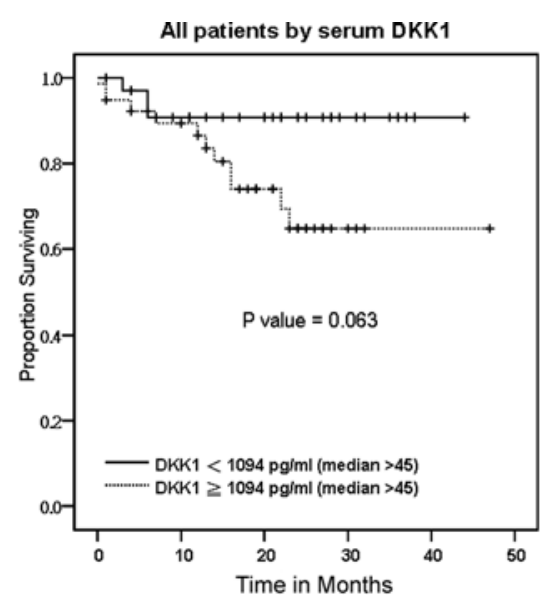

B

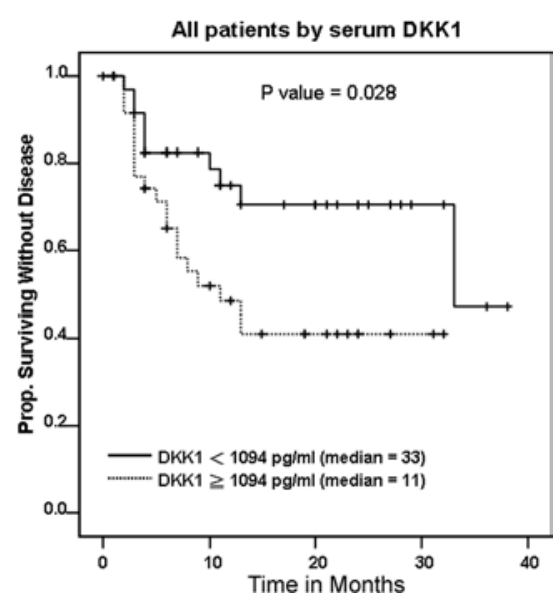

Figure 2. Kaplan-Meier plots for the correlation of DKK1 expression with overall survival (OS) and disease-free survival (DFS). (A) Correlation between OS and UC patients with low-serum DKK1 ( $<1,049$ pg/ml) vs. high-serum DKK1 ( $\geq 1,049 \mathrm{pg} / \mathrm{ml})$. (B) Correlation between DFS and UC patients with low-serum DKK1 $(<1,049 \mathrm{pg} / \mathrm{ml})$ vs. high-serum DKK1 $(\geq 1,049 \mathrm{pg} / \mathrm{ml})$. The p-values are from log-rank tests.

Table III. Univariate and multivariate analyses for the disease-free survival (DFS) and overall survival (OS) of the urothelial carcinoma (UC) patients.

\begin{tabular}{|c|c|c|c|c|c|c|}
\hline & \multicolumn{3}{|c|}{ DFS of UC patients } & \multicolumn{3}{|c|}{ OS of UC patients } \\
\hline & HR & $95 \% \mathrm{CI}$ & p-value & HR & $95 \% \mathrm{CI}$ & p-value \\
\hline \multicolumn{7}{|l|}{ Univariate analysis } \\
\hline Age (1 year) & 1.00 & $0.97-1.03$ & 0.970 & 1.06 & $0.99-1.12$ & 0.06 \\
\hline Gender (male vs. female) & 1.24 & $0.47-3.25$ & 0.670 & 0.48 & $0.16-1.42$ & 0.18 \\
\hline Cigarette smoking (never vs. ever) & 0.77 & $0.31-1.89$ & 0.570 & 0.55 & $0.12-2.46$ & 0.43 \\
\hline Clinical stage (non-muscle invasive vs. muscle invasive) & 1.12 & $0.54-2.33$ & 0.760 & 1.02 & $0.36-2.93$ & 0.96 \\
\hline Histological grade (high vs. low) & 1.55 & $0.66-3.65$ & 0.310 & $\mathrm{~N} / \mathrm{A}$ & N/A & N/A \\
\hline Serum DKK1 level (1 pg/ml) & 1.00 & $1.000-1.001$ & 0.007 & 1.00 & $0.99-1.00$ & 0.07 \\
\hline Serum DKK1 level ( $\geq 1,049$ vs. $<1,049$ pg/ml) & 2.44 & $1.10-5.40$ & 0.028 & 3.37 & $0.94-12.11$ & 0.06 \\
\hline \multicolumn{7}{|l|}{ Multivariate analysis } \\
\hline Age (1 year) & 0.99 & $0.97-1.03$ & 0.900 & 1.05 & $0.96-1.12$ & 0.14 \\
\hline Gender (male vs. female) & 1.47 & $0.52-4.13$ & 0.470 & 0.94 & $0.30-2.99$ & 0.92 \\
\hline Cigarette smoking (never vs. ever) & 0.72 & $0.28-1.81$ & 0.480 & 0.90 & $0.18-4.58$ & 0.90 \\
\hline Clinical stage (non-muscle invasive vs. muscle invasive) & 1.06 & $0.51-2.20$ & 0.878 & 0.39 & $0.12-1.28$ & 0.12 \\
\hline Histological grade (high vs. low) & 1.47 & $0.60-3.64$ & 0.410 & $\mathrm{~N} / \mathrm{A}$ & N/A & N/A \\
\hline Serum DKK1 level ( $\geq 1,049$ vs. $<1,049$ pg/ml) & 2.36 & $1.06-5.25$ & 0.035 & 2.70 & $0.74-9.90$ & 0.13 \\
\hline
\end{tabular}

HR, hazard ratio; CI, confidence interval.

of DKK1 was higher in the UC tissues when compared to the normal tissues (Fig. 3B).

\section{Discussion}

In the present study, the expression of DKK1 in UC patients was investigated. Serum DKK1 levels in UC patients were higher than those in the control individuals. Serum DKK1 levels were also higher in the UC patients with muscle-invasive and high-grade tumors than those in the controls. A high serum DKK1 level also appeared to be correlated with poor
DFS in the UC patients. In addition, high expression of DKK1 mRNA was also demonstrated in UC tissues using RT-PCR, and the expression of DKK1 protein in UC tissues was higher than that in the adjacent normal tissues as analyzed by Western blotting. This is the first report of high DKK1 expression in serum and in UC tissue from patients with UC. In addition, the elevation in DKK1 expression appeared to be correlated with clinical stage and histological grade.

DKK1 is a secreted protein that functions as a negative regulator of the Wnt/ $\beta$-catenin signaling, which is aberrantly activated in most human colon cancers and a number of other 
A
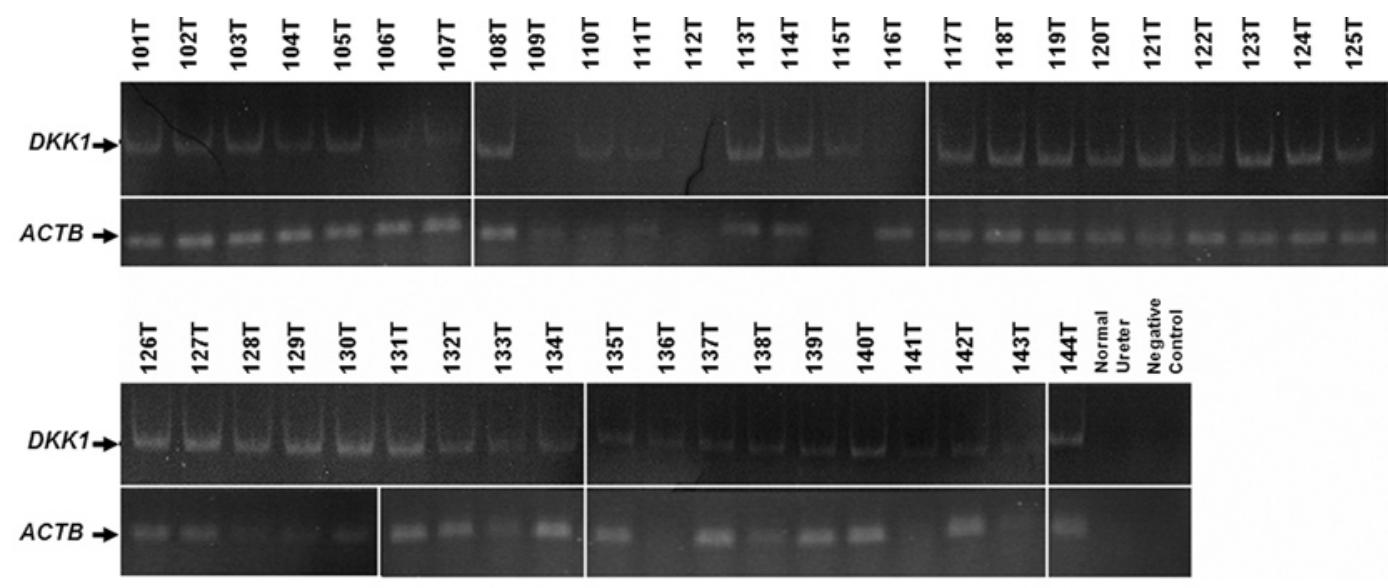

B

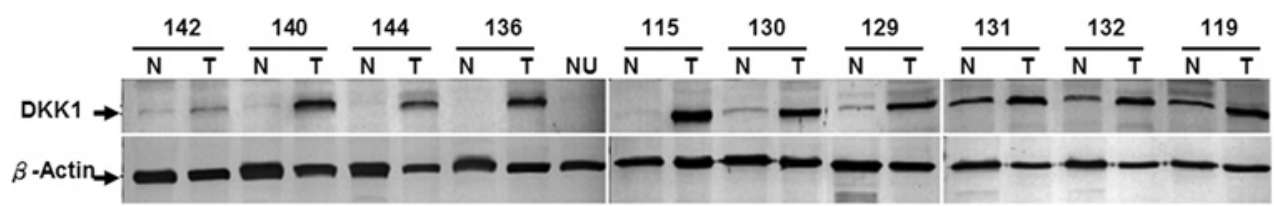

Figure 3. Detection of DKK1 expression in UC tissues. (A) Detection of DKK1 expression in UC tissues by RT-PCR. (B) Detection of DKK1 expression in UC tissues and adjacent normal tissues by Western blotting. N, adjacent normal tissue; T, UC tissue; NU, normal ureter.

carcinomas $(26,27)$. In human urothelia carcinoma, Wnt antogonists, Wif-1 and negative regulators of $\mathrm{Wnt} / \beta$-catenin signaling, sFRP1, sFRP2, sFRP4, sFRP5 and APC, have been reported to be down-regulated, suggesting that their functional loss might play an important role in cancer pathogenesis through aberrant canonical Wnt/ $\beta$-catenin pathway activation. In addition, DKK1 has been shown to be a downstream target of the $\beta$-catenin/TCF pathway, to participate in a negative feedback loop in Wnt signaling and to be strongly localized in a zone directly adjacent to the region where Wnt/ $\beta$-catenin signaling is active $(28,29)$. Taken together, these findings imply a mechanism in the zone of the tumor and adjacent cells whereby $\mathrm{Wnt} / \beta$-catenin pathway activation restricts itself through the induction of DKK1, resulting in an elevated DKK1 expression level. In agreement with this, previous studies on multiple myeloma (30), lung, esophageal (10) and hepatocellular carcinomas (31), estrogen and progesterone receptor-negative [ER(-)/PR(-)] breast cancer (7), and cervical, endometrial (8) and kidney cancers (7) have revealed that DKK1 is preferentially expressed in a great majority of cancer cases. These studies have established DKK1 as a potential prognostic and diagnostic marker for cancer patient cohorts with poor prognosis.

Although high expression of DKK1 appeared to be associated with DFS in this study it only showed a marginal association with OS in UC patients. This may be due to the short follow-up time ( $<3$ years) in the present study. Given that individuals with non-muscle invasive disease are at low risk of death and those who have muscle-invasive disease benefit from the successful therapy of radical surgery and urinary diversion, numerous clinical series have demonstrated a favorable 5-year prognosis for UC patients (32). Therefore, a possible reason for the lack of statistical significance in this setting may be the small number of deaths that were confirmed during the limited 3 -year follow-up of these UC patients. In addition, notably, the present study failed to find any statistically significant rela- tionship between the serum DKK1 level and any of the other variables measured, including age, gender and smoking status.

Although most UC patients are non-muscle invasive at the time of being diagnosed and are able to be treated by aggressive management such as surgical removal of the tumor, the recurrence and progression of UC are not easily diagnosed often resulting in negative consequences for patients. In the present study, DKK1 was found to be elevated in the sera and UC tissues of UC patients. Therefore, the detection of DKK1 expression in serum is a potential index for the recurrence or progression of UC. In addition, the inhibition of DKK1 may be a possible therapeutic target for UC in the future.

\section{Acknowledgements}

This study was supported by the Chiayi Christian Hospital grant R96-12.

\section{References}

1. Arrizabalaga M, Navarro J, Mora M, Castro M, Extramiana J, Manas A, Diez J and Paniagua P: [Transitional carcinomas of the urinary tract: synchronous and metachronous lesions]. Actas Urol Esp 18: 782-796, 1994.

2. Shen CH, Wang YH, Wang WC, Jou YC, Hsu HS, Hsieh HY and Chiou HY: Inducible nitric oxide synthase promoter polymorphism, cigarette smoking, and urothelial carcinoma risk. Urology 69: 1001-1006, 2007.

3. Herr HW: Natural history of superficial bladder tumors: 10- to 20-year follow-up of treated patients. World J Urol 15: 84-88, 1997.

4. Pashos CL, Botteman MF, Laskin BL and Redaelli A: Bladder cancer: epidemiology, diagnosis, and management. Cancer Pract 10: 311-322, 2002.

5. Morey SS: American Urological Association issues guidelines on the management of bladder cancer. Am Fam Physician 61: 3734-3736, 2000.

6. Aguilera O, Fraga MF, Ballestar E, Paz MF, Herranz M, Espada J Garcia JM, Munoz A, Esteller M and Gonzalez-Sancho JM: Epigenetic inactivation of the Wnt antagonist DICKKOPF-1 (DKK-1) gene in human colorectal cancer. Oncogene 25: 4116-4121, 2006. 
7. Forget MA, Turcotte S, Beauseigle D, Godin-Ethier J, Pelletier S, Martin J, Tanguay S and Lapointe R: The Wnt pathway regulator DKK1 is preferentially expressed in hormone-resistant breast tumours and in some common cancer types. Br J Cancer 96: 646-653, 2007.

8. Jiang T, Wang S, Huang L and Zhang S: Clinical significance of serum DKK-1 in patients with gynecological cancer. Int J Gynecol Cancer 19: 1177-1181, 2009.

9. Patil MA, Chua MS, Pan KH, Lin R, Lih CJ, Cheung ST, Ho C, Li R, Fan ST, Cohen SN, Chen X and So S: An integrated data analysis approach to characterize genes highly expressed in hepatocellular carcinoma. Oncogene 24: 3737-3747, 2005.

10. Yamabuki $\mathrm{T}$, Takano A, Hayama S, Ishikawa N, Kato $\mathrm{T}$, Miyamoto M, Ito T, Ito $\mathrm{H}$, Miyagi $\mathrm{Y}$, Nakayama $\mathrm{H}$, Fujita $\mathrm{M}$, Hosokawa M, Tsuchiya E, Kohno N, Kondo S, Nakamura Y and Daigo Y: Dikkopf-1 as a novel serologic and prognostic biomarker for lung and esophageal carcinomas. Cancer Res 67: 2517-2525, 2007.

11. Niida A, Hiroko T, Kasai M, Furukawa Y, Nakamura Y, Suzuki Y, Sugano S and Akiyama T: DKK1, a negative regulator of Wnt signaling, is a target of the beta-catenin/TCF pathway. Oncogene 23: 8520-8526, 2004.

12. Gonzalez-Sancho JM, Aguilera O, Garcia JM, Pendas-Franco N, Pena C, Cal S, Garcia de Herreros A, Bonilla F and Munoz A: The Wnt antagonist DICKKOPF-1 gene is a downstream target of beta-catenin/TCF and is downregulated in human colon cancer. Oncogene 24: 1098-1103, 2005.

13. Dulaimi E, Uzzo RG, Greenberg RE, Al-Saleem T and Cairns P: Detection of bladder cancer in urine by a tumor suppressor gene hypermethylation panel. Clin Cancer Res 10: 1887-1893, 2004.

14. Kastritis E, Murray S, Kyriakou F, Horti M, Tamvakis N, Kavantzas N, Patsouris ES, Noni A, Legaki S, Dimopoulos MA and Bamias A: Somatic mutations of adenomatous polyposis coli gene and nuclear b-catenin accumulation have prognostic significance in invasive urothelial carcinomas: evidence for Wnt pathway implication. Int J Cancer 124: 103-108, 2009.

15. Marsit CJ, Karagas MR, Andrew A, Liu M, Danaee H, Schned AR, Nelson HH and Kelsey KT: Epigenetic inactivation of SFRP genes and TP53 alteration act jointly as markers of invasive bladder cancer. Cancer Res 65: 7081-7085, 2005.

16. Maruyama R, Toyooka S, Toyooka KO, Harada K, Virmani AK, Zochbauer-Muller S, Farinas AJ, Vakar-Lopez F, Minna JD, Sagalowsky A, Czerniak B and Gazdar AF: Aberrant promoter methylation profile of bladder cancer and its relationship to clinicopathological features. Cancer Res 61: 8659-8663, 2001.

17. Stoehr R, Wissmann C, Suzuki H, Knuechel R, Krieg RC, Klopocki E, Dahl E, Wild P, Blaszyk H, Sauter G, Simon R, Schmitt R, Zaak D, Hofstaedter F, Rosenthal A, Baylin SB, Pilarsky $\mathrm{C}$ and Hartmann A: Deletions of chromosome 8p and loss of sFRP1 expression are progression markers of papillary bladder cancer. Lab Invest 84: 465-478, 2004.

18. Urakami S, Shiina H, Enokida H, Kawakami T, Kawamoto K, Hirata H, Tanaka Y, Kikuno N, Nakagawa M, Igawa M and Dahiya R: Combination analysis of hypermethylated Wnt-antagonist family genes as a novel epigenetic biomarker panel for bladder cancer detection. Clin Cancer Res 12: 2109-2116, 2006.

19. Urakami S, Shiina H, Enokida H, Kawakami T, Tokizane T, Ogishima T, Tanaka Y, Li LC, Ribeiro-Filho LA, Terashima M, Kikuno N, Adachi H, Yoneda T, Kishi H, Shigeno K, Konety BR, Igawa $\mathrm{M}$ and Dahiya R: Epigenetic inactivation of Wnt inhibitory factor-1 plays an important role in bladder cancer through aberrant canonical Wnt/beta-catenin signaling pathway. Clin Cancer Res 12: 383-391, 2006.
20. Kakiuchi S, Daigo Y, Ishikawa N, Furukawa C, Tsunoda T, Yano S, Nakagawa K, Tsuruo T, Kohno N, Fukuoka M, Sone S and Nakamura Y: Prediction of sensitivity of advanced non-small cell lung cancers to gefitinib (Iressa, ZD1839). Hum Mol Genet 13: 3029-3043, 2004.

21. Kakiuchi S, Daigo Y, Tsunoda T, Yano S, Sone S and Nakamura Y: Genome-wide analysis of organ-preferential metastasis of human small cell lung cancer in mice. Mol Cancer Res 1: 485-499, 2003.

22. Kikuchi T, Daigo Y, Ishikawa N, Katagiri T, Tsunoda T, Yoshida $\mathrm{S}$ and Nakamura Y: Expression profiles of metastatic brain tumor from lung adenocarcinomas on cDNA microarray. Int J Oncol 28: 799-805, 2006.

23. Kikuchi T, Daigo Y, Katagiri T, Tsunoda T, Okada K, Kakiuchi S, Zembutsu H, Furukawa Y, Kawamura M, Kobayashi K, Imai K and Nakamura Y: Expression profiles of non-small cell lung cancers on cDNA microarrays: identification of genes for prediction of lymph-node metastasis and sensitivity to anti-cancer drugs. Oncogene 22: 2192-2205, 2003.

24. Taniwaki M, Daigo Y, Ishikawa N, Takano A, Tsunoda T, Yasui W, Inai K, Kohno N and Nakamura Y: Gene expression profiles of small-cell lung cancers: molecular signatures of lung cancer. Int J Oncol 29: 567-575, 2006.

25. Yamabuki T, Daigo $\mathrm{Y}$, Kato $\mathrm{T}$, Hayama $\mathrm{S}$, Tsunoda $\mathrm{T}$, Miyamoto M, Ito T, Fujita M, Hosokawa M, Kondo $S$ and Nakamura Y: Genome-wide gene expression profile analysis of esophageal squamous cell carcinomas. Int J Oncol 28: 1375-1384, 2006.

26. Moon RT, Kohn AD, De Ferrari GV and Kaykas A: WNT and beta-catenin signalling: diseases and therapies. Nat Rev Genet 5: 691-701, 2004.

27. Reya $\mathrm{T}$ and Clevers $\mathrm{H}$ : Wnt signalling in stem cells and cancer. Nature 434: 843-850, 2005.

28. Aman A and Piotrowski T: Wnt/beta-catenin and Fgf signaling control collective cell migration by restricting chemokine receptor expression. Dev Cell 15: 749-761, 2008.

29. Chamorro MN, Schwartz DR, Vonica A, Brivanlou AH, Cho KR and Varmus HE: FGF-20 and DKK1 are transcriptional targets of beta-catenin and FGF-20 is implicated in cancer and development. EMBO J 24: 73-84, 2005.

30. Politou MC, Heath DJ, Rahemtulla A, Szydlo R, Anagnostopoulos A, Dimopoulos MA, Croucher PI and Terpos E: Serum concentrations of Dickkopf-1 protein are increased in patients with multiple myeloma and reduced after autologous stem cell transplantation. Int J Cancer 119: 1728-1731, 2006.

31. Yu B, Yang X, Xu Y, Yao G, Shu H, Lin B, Hood L, Wang H, Yang S, Gu J, Fan J and Qin W: Elevated expression of DKK1 is associated with cytoplasmic/nuclear beta-catenin accumulation and poor prognosis in hepatocellular carcinomas. J Hepatol 50: 948-957, 2009

32. Stein JP, Lieskovsky G, Cote R, Groshen S, Feng AC, Boyd S, Skinner E, Bochner B, Thangathurai D, Mikhail M, Raghavan D and Skinner DG: Radical cystectomy in the treatment of invasive bladder cancer: long-term results in 1,054 patients. J Clin Oncol 19: 666-675, 2001 